\title{
Latitudinal extent of the January 2005 solar proton event in the Northern Hemisphere from satellite observations of hydroxyl
}

\author{
P. T. Verronen ${ }^{1}$, C. J. Rodger ${ }^{2}$, M. A. Clilverd ${ }^{3}$, H. M. Pickett ${ }^{4}$, and E. Turunen ${ }^{5}$ \\ ${ }^{1}$ Earth Observation, Finnish Meteorological Institute, Helsinki, Finland \\ ${ }^{2}$ Physics Department, University of Otago, Dunedin, New Zealand \\ ${ }^{3}$ Physical Sciences Division, British Antarctic Survey (NERC), Cambridge, UK \\ ${ }^{4}$ Jet Propulsion Laboratory, California Institute of Technology, Pasadena, CA, USA \\ ${ }^{5}$ Sodankylä Geophysical Observatory, University of Oulu, Sodankylä, Finland
}

Received: 10 May 2007 - Revised: 8 October 2007 - Accepted: 18 October 2007 - Published: 6 November 2007

\begin{abstract}
We utilise hydroxyl observations from the MLS/Aura satellite instrument to study the latitudinal extent of particle forcing in the northern polar region during the January 2005 solar proton event. MLS is the first satellite instrument to observe $\mathrm{HO}_{\mathrm{x}}$ changes during such an event. We also predict the hydroxyl changes with respect to the magnetic latitude by the Sodankylä Ion and Neutral Chemistry model, estimating the variable magnetic cutoff energies for protons using a parameterisation based on magnetosphere modelling and the planetary magnetic index $K_{p}$. In the middle and lower mesosphere, $\mathrm{HO}_{\mathrm{x}}$ species are good indicators of the changes in the atmosphere during solar proton events, because they respond rapidly to both increases and decreases in proton forcing. Also, atmospheric transport has a negligible effect on $\mathrm{HO}_{\mathrm{x}}$ because of its short chemical lifetime. The observations indicate the boundary of the proton forcing and a transition region, from none to the "full" effect, which ranges from about 57 to 64 degrees of magnetic latitude. When saturating the rigidity cutoff $K_{p}$ at 6 in the model, as suggested by earlier studies using observations of cosmic radio noise absorption, the equatorward boundary of the transition region is offset by $\approx 2$ degrees polewards compared with the data, thus the latitudinal extent of the proton forcing in the atmosphere is underestimated. However, the model predictions are in reasonable agreement with the MLS measurements when the $K_{p}$ index is allowed to vary within its nominal range, i.e., from 1 to 9 in the cutoff calculation.
\end{abstract}

Keywords. Atmospheric composition and structure (Middle atmosphere - composition and chemistry) - Ionosphere (Particle precipitation) - Magnetospheric physics (Polar cap phenomena)

Correspondence to: P. T. Verronen

(pekka.verronen@fmi.fi)

\section{Introduction}

Solar proton events (SPE) correspond to solar coronal mass ejections during which a large amount of protons and heavier ions are emitted (Reames, 1999), sometimes toward the Earth. Solar protons entering the Earth's magnetosphere precipitate into the polar cap areas (Patterson et al., 2001). The protons can have very high energies, i.e. tens of $\mathrm{MeV}$, leading to energy deposition in the mesosphere and stratosphere. Thus they provide a direct connection between the Sun and the Earth's middle atmosphere. SPE are relatively sporadic but more probable during solar maxima, and they are extreme examples of solar forcing on the middle atmosphere. Between 1976 and 2006 there were 222 recorded SPE, on average $\sim 80$ an 11-year solar cycle, with flux and energies varying significantly from SPE to SPE (see, e.g., http://umbra.nascom.nasa.gov/SEP/).

In the middle atmosphere, SPE, and particle precipitation in general, lead to production of 1) odd hydrogen $\mathrm{HO}_{\mathrm{x}}$ $\left(\mathrm{H}+\mathrm{OH}+\mathrm{HO}_{2}\right)$ through chemistry associated with ion pair production, water cluster ion formation, and subsequent neutralisation, and 2) odd nitrogen $\mathrm{NO}_{\mathrm{x}}\left(\mathrm{N}+\mathrm{NO}+\mathrm{NO}_{2}\right)$ through dissociation of molecular nitrogen via charged particle impact and ion chemistry (Solomon et al., 1981; Rusch et al., 1981). $\mathrm{HO}_{\mathrm{x}}$ and $\mathrm{NO}_{\mathrm{x}}$ play a key role in ozone balance of the middle atmosphere because they destroy odd oxygen through catalytic reactions (e.g. Grenfell et al., 2006). Both shortterm and long-term ozone depletion has been observed after major SPE (Reid et al., 1991; Jackman et al., 2001; Seppälä et al., 2004; Verronen et al., 2005).

Guided by the Earth's magnetic field, the protons penetrate the atmosphere at high magnetic latitudes, the effects covering the polar caps more or less uniformly. According to the Størmer theory, every geomagnetic latitude has a cutoff limit which the rigidity (defined as momentum per charge) of an incoming particle must exceed in order it to reach that

Published by Copernicus Publications on behalf of the European Geosciences Union. 
particular location (Størmer, 1930). Penetration to lower latitudes requires higher rigidities, and a certain latitude is affected by particles having rigidity equal to, or higher than the corresponding cutoff. The cutoff rigidity varies also with time, being dependent on the interplanetary magnetic field as well as on the Earth's internal magnetic field, on timescales from minutes to years (Smart and Shea, 2003; Kress et al., 2004). Geomagnetic storms, for example, tend to compress the magnetosphere and lower the cutoff rigidity for a given latitude (e.g. Birch et al., 2005, and references therein). The relatively sharp transition region from practically-total cutoff to none is located approximately between $60^{\circ}$ and $65^{\circ}$ of magnetic latitude.

Observations of geomagnetic cutoff rigidities have generally been based on satellite or airborne measurements of particle fluxes (Ogliore et al., 2001; Dyer et al., 2003). However, few studies have considered the temporal variation, or attempted to model highly dynamical situations during magnetic storms. Comparison with theoretical predictions, based on particle tracing through the Earth's magnetic field, have shown that the predictions are in agreement with observations during low and medium levels of magnetic disturbance, but give higher cutoff latitudes (polewards) during strong disturbances (Smart and Shea, 2001; Birch et al., 2005). Recently, Rodger et al. (2006) have compared theoretical cutoff rigidities and ground-based ionospheric measurements. Although general agreement was found, the calculations overestimated the cutoff energies during disturbed geomagnetic conditions when the planetary magnetic index $K_{p}$ was greater than 5.

In atmospheric modelling, SPE are typically simulated by forcing the atmosphere at latitudes above $60^{\circ}$, in the both hemispheres (e.g. Jackman et al., 1995). However, to date there are few studies addressing in detail latitudinal extents of the atmospheric effects through satellite observations. Ground-based ionospheric observations have been used by, e.g., Rodger et al. (2006), but these observations are naturally restricted in location. In any case, it is important to define the cutoff latitudes in magnetic coordinates because in geographic coordinates the latitudinal extent of forcing varies strongly with the longitude (Dobbin et al., 2006). When looking for an indicator of the changes in the atmosphere during solar proton events, $\mathrm{HO}_{\mathrm{x}}$ species are good candidates because 1) their night-time concentrations can be significantly increased by moderate proton forcing (Solomon et al., 1981), and 2) the chemical lifetime of the $\mathrm{HO}_{\mathrm{x}}$ family is less than $1 \mathrm{~h}$ in the middle atmosphere below $80 \mathrm{~km}$ (Brasseur and Solomon, 2005). Thus $\mathrm{HO}_{\mathrm{x}}$ responds rapidly to changes, both increases and decreases, in proton forcing. Further, atmospheric transport has a negligible effect on the $\mathrm{HO}_{\mathrm{x}}$ distribution because of its short chemical lifetime.

In this paper we study the latitudinal extent of solar proton forcing in the middle atmosphere by satellite observations of the atmospheric effects caused by the SPE which occurred in January 2005. Hydroxyl measurements by MLS/Aura in- strument are compared to results obtained from Sodankylä Ion and Neutral Chemistry model. In the model, the variations of geomagnetic cutoff are taken into account according to the method of Rodger et al. (2006), based on magnetosphere modelling and particle-tracing studies (we discuss this method in more detail in Sect. 4). In contrast to most previous studies, we now observe the "end" effects in the atmosphere, which is a new way to establish the variation of latitudinal limits of SPE forcing. Due to the strong diurnal variation of $\mathrm{HO}_{\mathrm{x}}$ concentration, the enhancements caused by SPE are most pronounced at night when the background $\mathrm{HO}_{\mathrm{x}}$ is at its lowest level (Solomon et al., 1981). The effects are also seen during daytime, but only when the proton forcing is especially strong. For this reason, we have chosen to utilise observations of night-time $\mathrm{OH}$ concentrations only.

\section{SPE of January 2005}

When considering the hydroxyl changes caused by the SPE, we note that protons depositing their energy between 90 and $50 \mathrm{~km}$ have energies approximately between 3 and $30 \mathrm{MeV}$ (e.g. Fig. 6.8 in Hargreaves, 1992, pp. 218). Figure 1a shows GOES proton flux measurements in late January for two of the most relevant energy channels, $E>5 \mathrm{MeV}$ and $E>10 \mathrm{MeV}$. Highest proton fluxes were observed around midnight on 17/18 January and around noon on 20 January. These flux values can now be contrasted with the cutoff energies at selected IGRF-determined magnetic latitudes, shown in Fig. 1b, which we estimate using the Rodger et al. (2006) method. In general, low cutoff and high flux coincide on 17-19 January, while during 20 January the cutoff is high. The rigidity cutoff prevents protons from significantly affecting the mesosphere at $61^{\circ} \mathrm{N}$ during the SPE. The situation is similar at $63^{\circ} \mathrm{N}$ most of the time, except on 17-19 January and during a shorter period around the midnight on 21/22 January. At those times the $K_{p}$ index, shown in Fig. 1c, increases and the cutoff energy drops so that mesosphere experiences the full impact of the protons. At $65^{\circ} \mathrm{N}$ the cutoff is generally $<10 \mathrm{MeV}$, so that mesosphere is at least partially affected throughout the whole SPE. As in the case of $63^{\circ} \mathrm{N}$, the cutoff drops dramatically during two periods of time, on 17-19 January and around midnight on 21/22 January, and the mesosphere experiences the full impact of the proton precipitation.

\section{Magnetic cutoff transition from MLS hydroxyl data}

The Microwave Limb Sounder (MLS) instrument on board the Aura satellite was launched in July 2004 (Pickett et al., 2006, and references therein). In this work we have used the OH measurements made in January 2005, to study the latitudinal extent of the SPE that occurred at the time. MLS is the first satellite instrument that has been able to monitor the 

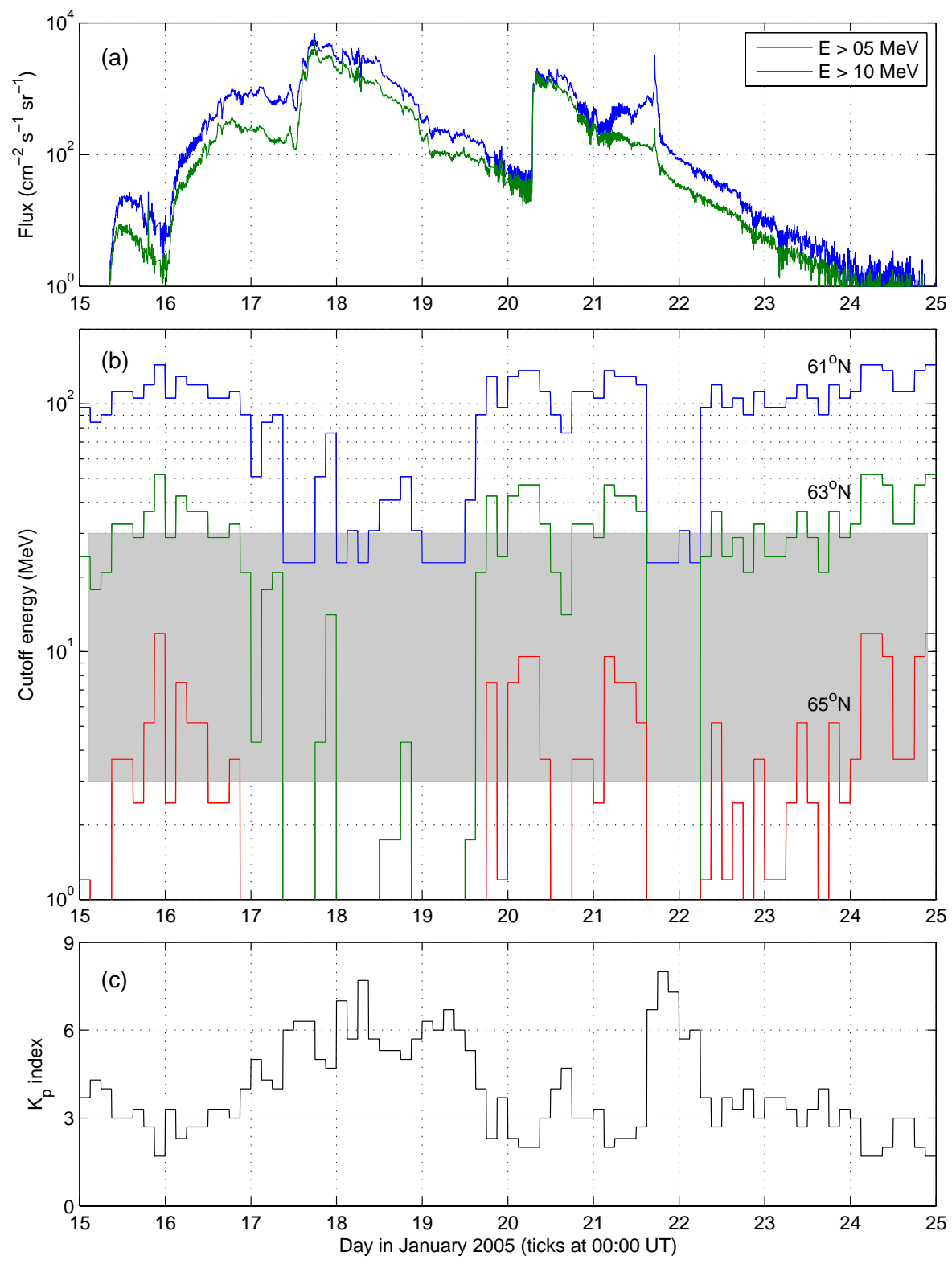

Fig. 1. (a) Proton fluxes measured at Geostationary Orbit by the GOES-11 satellite. (b) Estimated cutoff energies at selected magnetic latitudes. The grey area indicates the approximative energy range of protons depositing their energy in the mesosphere, i.e. 3-30 MeV. (c) Planetary magnetic index $K_{p}$.

changes in $\mathrm{HO}_{\mathrm{x}}$ concentrations caused by an SPE, with coverage across the mesospheric altitudes where the SPE-caused changes are expected to be the largest. Version 1.51 data were selected for latitudes between $50^{\circ} \mathrm{N}$ and $70^{\circ} \mathrm{N}$ and then screened according to the MLS Data Quality and Description Document (Livesey et al., 2005). The data above $60 \mathrm{~km}$ are not recommended for general use, because negative retrieved concentrations are frequently present above $60 \mathrm{~km}$ in many of the daytime retrievals. The next version of the retrieval software (2.21) is operational and corrects these problems by increasing the height resolution above $60 \mathrm{~km}$ from $3 \mathrm{lev}$ els/decade of pressure to 6 levels/decade of pressure. This change improves the residuals between the experimental radiance and that computed from the forward model and also improves the convergence of the retrieval. Full reprocessing of the data is still in progress. For the present study, we made comparisons of the two versions, 1.51 and 2.21, for the SPE-induced $\mathrm{OH}$ profiles in the mesosphere and found no significant differences. We are therefore confident that the $\mathrm{OH}$ data used in this study are reliable up to $90 \mathrm{~km}$ altitude. 

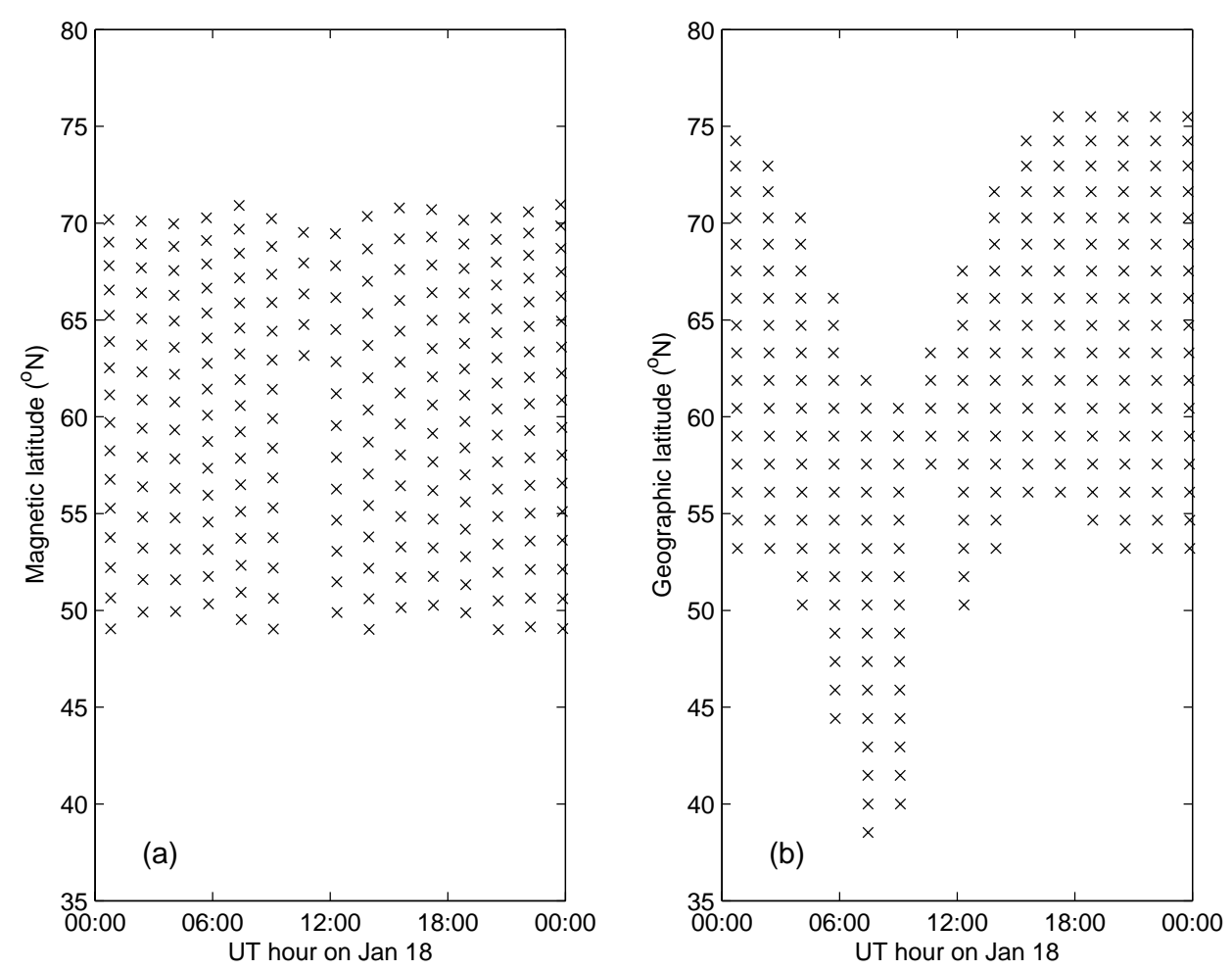

Fig. 2. (a) Locations of MLS/Aura observations at magnetic latitudes between about $50-70^{\circ} \mathrm{N}$ on 18 January. (b) The geographic latitudes of the same observations.

The geographic coordinates of the observations were first converted to magnetic ones, so that the measurements could be binned according to magnetic latitude. We make use of Corrected GeoMagnetic (CGM) coordinates based on the Definite/International Geomagnetic Reference Field (DGRF/IGRF) for 2005 at $100 \mathrm{~km}$ altitude, determined using the GEOPACK software routines. Figure 2 shows, as an example, the locations of the observations made on 18 January. Vertical rows of observations indicate the orbits of the satellite and are separated by $\approx 90 \mathrm{~min}$. Subsequent observations on the same orbit are separated by $\approx 25 \mathrm{~s}$. Note that the plot shows data for magnetic latitudes $50-70^{\circ} \mathrm{N}$ only, and that the geographic extent of the same observations is from $39^{\circ} \mathrm{N}$ to $75^{\circ} \mathrm{N}$. The data coverage is similar for the other days of the SPE. Because the Aura satellite is in a sun-synchronous orbit, night-time observations are sampled at about the same local time, 02:30-03:00, for the latitude region of interest. On the other hand, different longitudes are observed during successive orbits.

Left panels of Fig. 3 present the MLS hydroxyl concentrations at selected magnetic latitudes between $57^{\circ} \mathrm{N}$ and $65^{\circ} \mathrm{N}$, while the right panels show the change from values observed on 10-15 January, i.e., the change relative to 5 days before, when GOES measured proton fluxes were very low. These observations can be used to define the transition region of proton forcing where the magnitude of the magnetic cutoff is dependent on the latitude. The effect of magnetic cutoff is evident by contrasting the concentrations at different latitudes. At latitudes equal to and lower than $57^{\circ} \mathrm{N}$ (the lower latitudes are not shown) the proton forcing produces relatively small or no increase of $\mathrm{OH}$, respectively, while increasing latitude corresponds to increasing enhancements. Largest increases are seen at the higher latitudes, $65^{\circ} \mathrm{N}$ and above, on $18 \mathrm{Jan}-$ uary when the proton flux is highest. Note that at $65^{\circ} \mathrm{N}$ the second largest increase is seen on 21 January corresponding to high proton fluxes, while at the lower latitudes it is seen on 22 January. This is due to rigidity cutoff being high on 21 January and diminishing the proton effect in the transition region, so that on 22 January a lower flux combined with a very low rigidity cutoff energy result in larger changes of $\mathrm{OH}$ than those seen on 21 January. The narrow layer of $\mathrm{OH}$ observed at $80 \mathrm{~km}$ is a natural feature of the night-time mesosphere (Pickett et al., 2006). The layer is due to reaction of long-lived $\mathrm{H}$ atoms with ozone and is not related to energetic particles or ion chemistry.

Figure 4 shows the night-time hydroxyl concentrations at 63 and $74 \mathrm{~km}$ for selected days of January. The data for 15 January indicates relatively uniform concentrations before the onset of the SPE with respect to latitude. On 18 January (marked as Day 18 in the figure caption), when the proton 

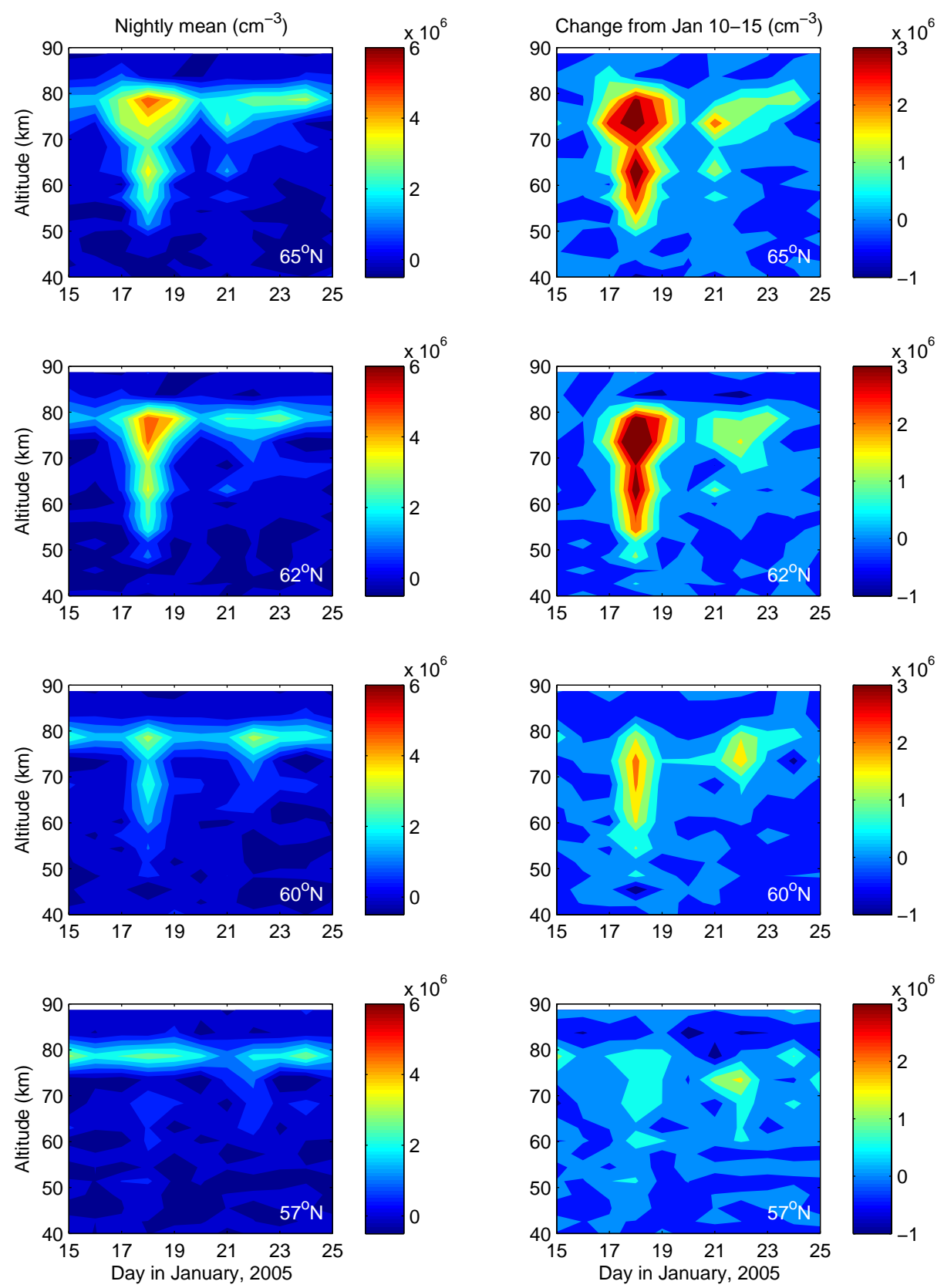

Fig. 3. Left panels: MLS/Aura observations of night-time $\mathrm{OH}$ at selected magnetic latitudes. The data has been averaged to $2^{\circ}$-wide latitude bins at 19:00-05:00 UT for each day. The local time of the observations ranges between 02:30 and 03:00. Right panels: the change from the average of values observed on 10-15 January.

forcing is at its strongest, the data shows a clear increase of $\mathrm{OH}$ from approximately $57^{\circ} \mathrm{N}$ to $64^{\circ} \mathrm{N}$. Similar increases with latitude are also seen on 19 January and 21 January, although the magnitude of the increase is lower due to smaller fluxes of protons. On 19 January, the cutoff transition begins at about $59^{\circ} \mathrm{N}$, i.e. at a higher latitude than on 18 January although the cutoffs are similar. This is because the $\mathrm{OH}$ pro- duced by the lower flux on 19 January does not exceed the background concentrations at latitudes lower than $59^{\circ} \mathrm{N}$. It should be noted that in the cases other than 18 January the standard deviation of the averaged data is generally larger than the observed increase, so that definite conclusions are not easily made. 

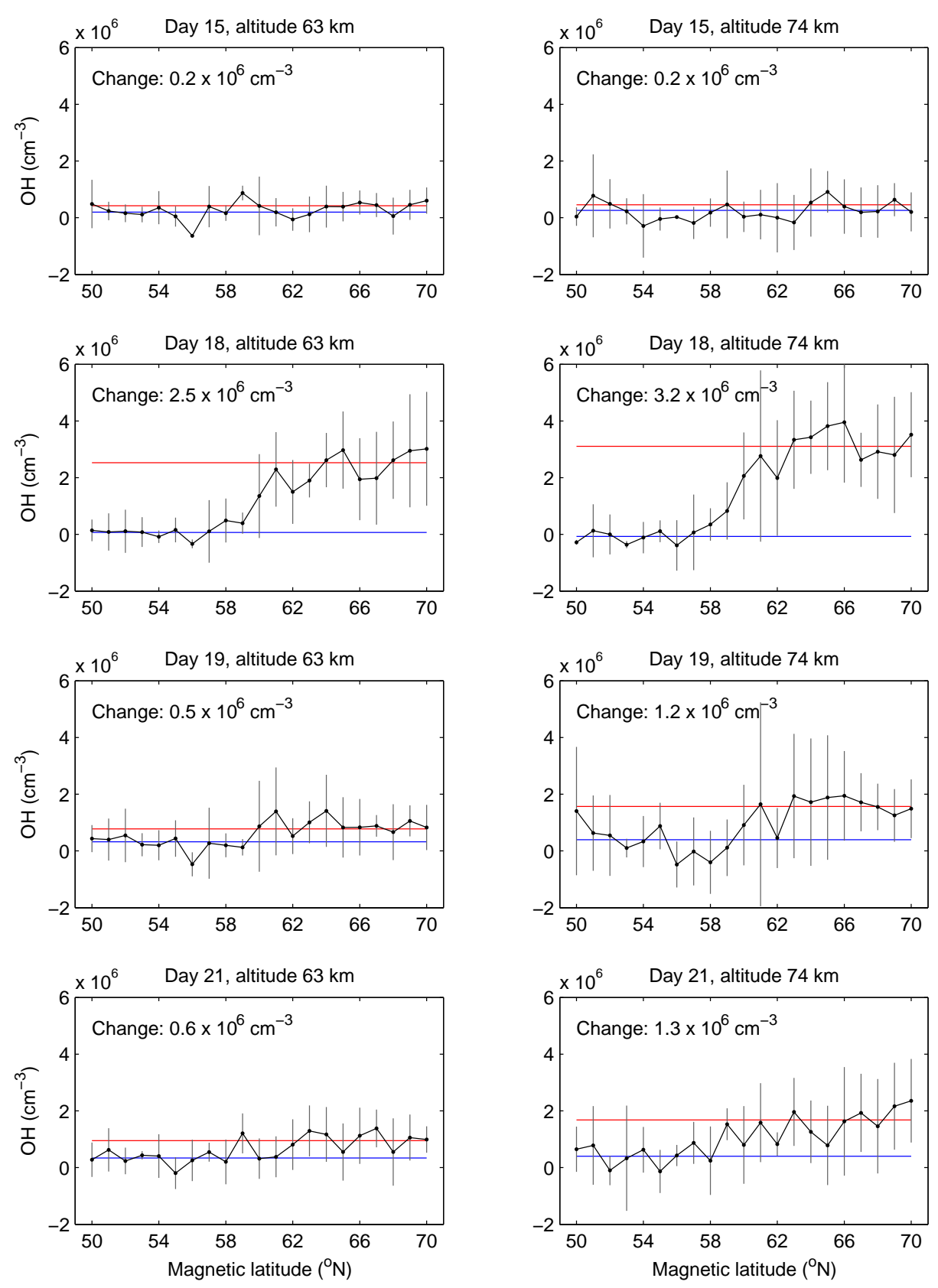

Fig. 4. Night-time $\mathrm{OH}$ concentrations at 63 and $74 \mathrm{~km}$ for selected days of January. The data has been averaged to $1^{\circ}$-wide latitude bins at 00:00-06:00 UT for each day (black dots). The local time of the observations ranges between 02:30 and 03:00. Standard deviations are shown with vertical gray lines. The blue and red lines indicate average values at $50-55^{\circ} \mathrm{N}$ and $65-70^{\circ} \mathrm{N}$, respectively, representing approximately the concentrations not affected and strongly affected by protons.

\section{Modelling the SPE effects in the magnetic cutoff tran- sition region}

The Sodankylä Ion and Neutral Chemistry model, also known as SIC, is a 1-D tool for ionosphere-atmosphere interaction studies. First version of the model was developed in the late 1980s for ionospheric data interpretation. A detailed description of the original SIC model, which solved the ion composition only, can be found in the work of Turunen et al. (1996). The latest version 6.9.0 solves the concentrations of 65 ions, of which 36 are positive and 29 negative, as well as 15 minor neutral species. The list of the modelled species 
Table 1. SIC model: modelled ions and minor neutral species.

$$
\begin{aligned}
& \mathrm{O}, \mathrm{O}\left({ }^{1} \mathrm{D}\right), \mathrm{O}_{2}\left({ }^{1} \Delta_{g}\right), \mathrm{O}_{3} \\
& \mathrm{~N}, \mathrm{~N}\left({ }^{2} \mathrm{D}\right), \mathrm{NO}, \mathrm{NO}_{2}, \mathrm{NO}_{3}, \mathrm{HNO}_{3}, \mathrm{~N}_{2} \mathrm{O}_{5} \\
& \mathrm{H}, \mathrm{OH}, \mathrm{HO}_{2}, \mathrm{H}_{2} \mathrm{O}_{2} \\
& \mathrm{O}^{+}, \mathrm{O}_{2}^{+}, \mathrm{O}_{4}^{+}, \mathrm{O}_{2}^{+}\left(\mathrm{H}_{2} \mathrm{O}\right), \mathrm{O}_{2}^{+} \mathrm{N}_{2}, \mathrm{O}_{2}^{+} \mathrm{CO}_{2}, \mathrm{O}_{2}^{+}\left(\mathrm{H}_{2} \mathrm{O}\right) \mathrm{N}_{2}, \mathrm{O}_{2}^{+}\left(\mathrm{H}_{2} \mathrm{O}\right) \mathrm{CO}_{2}, \mathrm{O}_{2}^{+}\left(\mathrm{H}_{2} \mathrm{O}\right)_{2} \\
& \mathrm{~N}^{+}, \mathrm{N}_{2}^{+}, \mathrm{NO}^{+}, \mathrm{NO}^{+}\left(\mathrm{N}_{2}\right), \mathrm{NO}^{+}\left(\mathrm{CO}_{2}\right), \mathrm{NO}^{+}\left(\mathrm{H}_{2} \mathrm{O}\right), \mathrm{NO}^{+}\left(\mathrm{H}_{2} \mathrm{O}\right)_{2}, \mathrm{NO}^{+}\left(\mathrm{H}_{2} \mathrm{O}\right)_{3}, \mathrm{NO}^{+}\left(\mathrm{H}_{2} \mathrm{O}\right)\left(\mathrm{N}_{2}\right), \\
& \mathrm{NO}^{+}\left(\mathrm{H}_{2} \mathrm{O}\right)\left(\mathrm{CO}_{2}\right), \mathrm{NO}^{+}\left(\mathrm{H}_{2} \mathrm{O}\right)_{2}\left(\mathrm{~N}_{2}\right), \mathrm{NO}^{+}\left(\mathrm{H}_{2} \mathrm{O}\right)_{2}\left(\mathrm{CO}_{2}\right) \\
& \mathrm{H}^{+}\left(\mathrm{H}_{2} \mathrm{O}\right), \mathrm{H}^{+}\left(\mathrm{H}_{2} \mathrm{O}\right)_{2}, \mathrm{H}^{+}\left(\mathrm{H}_{2} \mathrm{O}\right)_{3}, \mathrm{H}^{+}\left(\mathrm{H}_{2} \mathrm{O}\right)_{4}, \mathrm{H}^{+}\left(\mathrm{H}_{2} \mathrm{O}\right)_{5}, \mathrm{H}^{+}\left(\mathrm{H}_{2} \mathrm{O}\right)_{6}, \mathrm{H}^{+}\left(\mathrm{H}_{2} \mathrm{O}\right)_{7}, \mathrm{H}^{+}\left(\mathrm{H}_{2} \mathrm{O}\right)_{8} \\
& \mathrm{H}_{3} \mathrm{O}^{+}(\mathrm{OH}), \mathrm{H}_{3} \mathrm{O}^{+}(\mathrm{OH}) \mathrm{H}_{2} \mathrm{O}, \mathrm{H}_{3} \mathrm{O}^{+}(\mathrm{OH}) \mathrm{CO}_{2}, \mathrm{H}^{+}\left(\mathrm{H}_{2} \mathrm{O}\right)_{2}\left(\mathrm{CO}_{2}\right), \mathrm{H}^{+}\left(\mathrm{H}_{2} \mathrm{O}\right)_{2} \mathrm{~N}_{2}, \mathrm{H}^{+}\left(\mathrm{H}_{2} \mathrm{O}\right) \mathrm{CO}_{2}, \mathrm{H}^{+}\left(\mathrm{H}_{2} \mathrm{O}\right) \mathrm{N}_{2} \\
& \mathrm{O}^{-}, \mathrm{O}_{2}^{-}, \mathrm{O}_{3}^{-}, \mathrm{O}_{4}^{-}, \mathrm{O}^{-}\left(\mathrm{H}_{2} \mathrm{O}\right), \mathrm{O}_{2}^{-}\left(\mathrm{H}_{2} \mathrm{O}\right), \mathrm{O}_{2}^{-}\left(\mathrm{H}_{2} \mathrm{O}\right)_{2}, \mathrm{O}_{3}^{-}\left(\mathrm{H}_{2} \mathrm{O}\right) \\
& \mathrm{OH}^{-}, \mathrm{OH}^{-}\left(\mathrm{H}_{2} \mathrm{O}\right), \\
& \mathrm{CO}_{3}^{-}, \mathrm{CO}_{4}^{-}, \mathrm{CO}_{3}^{-}\left(\mathrm{H}_{2} \mathrm{O}\right), \mathrm{CO}_{3}^{-}\left(\mathrm{H}_{2} \mathrm{O}\right)_{2}, \mathrm{HCO}_{3}^{-} \\
& \mathrm{NO}_{2}^{-}, \mathrm{NO}_{3}^{-}, \mathrm{NO}_{3}^{-}(*), \mathrm{NO}_{3}^{-}\left(\mathrm{H}_{2} \mathrm{O}\right), \mathrm{NO}_{2}^{-}\left(\mathrm{H}_{2} \mathrm{O}\right), \mathrm{NO}_{3}^{-}\left(\mathrm{H}_{2} \mathrm{O}\right)_{2}, \mathrm{NO}_{3}^{-}\left(\mathrm{HNO}_{3}\right), \mathrm{NO}_{3}^{-}\left(\mathrm{HNO}_{3}\right)_{2}, \mathrm{NO}_{3}^{-}(\mathrm{HCl}) \\
& \mathrm{Cl}^{-}, \mathrm{ClO}^{-}, \mathrm{Cl}^{-}\left(\mathrm{H}_{2} \mathrm{O}\right), \mathrm{Cl}^{-}\left(\mathrm{CO}_{2}\right), \mathrm{Cl}^{-}(\mathrm{HCl})
\end{aligned}
$$

is given in Table 1. A recent, detailed description of SIC is given by Verronen et al. (2005) and Verronen (2006). Below we briefly summarise the main details of the model.

The altitude range of SIC is from 20 to $150 \mathrm{~km}$, with $1-\mathrm{km}$ resolution. The model includes a chemical scheme of several hundred reactions, and takes into account external forcing due to solar UV and soft X-ray radiation, electron and proton precipitation, and galactic cosmic rays. The background neutral atmosphere is generated using the MSISE-90 model (Hedin, 1991) and tables given by Shimazaki (1984). The solar flux is estimated by the SOLAR2000 model (Tobiska et al., 2000), version 2.27. The scattered component of the solar Lyman- $\alpha$ flux is included using the empirical approximation given by Thomas and Bowman (1986). The model includes a vertical transport scheme, as described by Chabrillat et al. (2002), which takes into account molecular and eddy diffusion. Within the transport code the molecular diffusion coefficients are calculated according to Banks and Kockarts (1973). Eddy diffusion coefficient profile can be varied using the parameterisation given by Shimazaki (1971).

Ionisation rate due to proton precipitation is calculated using GOES-11 satellite proton flux data, available from, e.g., the NOAA National Geophysical Data Center World Wide Web server at www.ngdc.noaa.gov/stp/stp.html. GOES satellites measure integrated proton fluxes above seven threshold values: $1,5,10,30,50,60$, and $100 \mathrm{MeV}$. These observations are converted to differential flux spectra using the exponential rigidity relation, and then ionisation rates are calculated using the empirical energy-range relation of protons (for details, see Verronen et al., 2005, and references therein). For magnetic latitudes higher than about $60^{\circ}$, the effects of geomagnetic cutoff are effectively negligible such that practically all energetic SPE protons are able to enter the atmosphere, thus the GOES flux measurements at geostationary orbit can be used (e.g. Hargreaves, 1992, p. 355-
359). For lower latitudes, it becomes necessary to consider the time-varying geomagnetic cutoff energy, which we calculate using a method described by Rodger et al. (2006). This method uses particle tracing studies by Smart and Shea (2003), who calculated the cutoff energies at a given International Geomagnetic Reference Fields (IGRF) McIlwain Lparameter at $450 \mathrm{~km}$ altitude using the $K_{p}$-dependent Tsyganenko magnetospheric field model (Tsyganenko, 1989), but with two modifications: 1 ) the rigidity cutoff is made to vary as $15.062 \times L^{-2}$ as observed by the SAMPEX instrument and 2) the upper limit for $K_{p}$ index in the rigidity model is $K_{p}=6$, i.e. the exceeding values are forced to $K_{p}=6$ in the calculations. This upper limit is selected through contrast with the November 2001 experimental observations. The results at $450 \mathrm{~km}$ are interpolated down to lower altitudes (for example $100 \mathrm{~km}$ ), following the approach outlined by Smart and Shea (2003). The Rodger method provides a cutoff energy, $E_{\text {cut }}$, for protons at a given geographical location, which we then use to modify differential spectra of protons simply by setting the flux equal to zero at energies lower than $E_{\text {cut }}$.

Ionisation caused by protons results in a set of initial ions, including $\mathrm{O}_{2}^{+}$, leading to formation of its hydrate $\mathrm{O}_{2}^{+}\left(\mathrm{H}_{2} \mathrm{O}\right)$ via $\mathrm{O}_{4}^{+}$. There are then a number of reaction pathways, with increasing degree of hydration and eventual recombination with an electron, as a result of which one water molecule can be converted into two odd hydrogen species, $\mathrm{OH}$ and $\mathrm{H}$ (for details, see Heaps, 1978; Solomon et al., 1981). These pathways are effective only at altitudes below about $80 \mathrm{~km}$, where the amount of water vapour is high enough so that cluster ions can be formed, and can be interrupted by recombination of the intermediate ions. At lower altitudes where negative ions are more abundant than free electrons, the positive ions favour negative ions in recombination, resulting in production of $\mathrm{HNO}_{3}$. A large part of the produced $\mathrm{HNO}_{3}$ is photodissociated to produce $\mathrm{OH}$, thus this pathway also adds 
Table 2. Locations of the model runs.

\begin{tabular}{cccc}
\hline Geo. lat. & Geo. long. & Mag. lat. & Mag. long. \\
\hline $59.95^{\circ} \mathrm{N}$ & $15.00^{\circ} \mathrm{W}$ & $60.00^{\circ} \mathrm{N}$ & $70.10^{\circ} \mathrm{E}$ \\
$60.95^{\circ} \mathrm{N}$ & $15.00^{\circ} \mathrm{W}$ & $61.00^{\circ} \mathrm{N}$ & $70.57^{\circ} \mathrm{E}$ \\
$62.05^{\circ} \mathrm{N}$ & $15.00^{\circ} \mathrm{W}$ & $62.00^{\circ} \mathrm{N}$ & $71.12^{\circ} \mathrm{E}$ \\
$63.03^{\circ} \mathrm{N}$ & $15.00^{\circ} \mathrm{W}$ & $63.00^{\circ} \mathrm{N}$ & $71.65^{\circ} \mathrm{E}$ \\
$64.01^{\circ} \mathrm{N}$ & $15.00^{\circ} \mathrm{W}$ & $64.00^{\circ} \mathrm{N}$ & $72.21^{\circ} \mathrm{E}$ \\
$64.97^{\circ} \mathrm{N}$ & $15.00^{\circ} \mathrm{W}$ & $65.00^{\circ} \mathrm{N}$ & $72.81^{\circ} \mathrm{E}$ \\
\hline
\end{tabular}

to odd hydrogen production. Similar pathways starting from the $\mathrm{NO}^{+}$ion exist. However, these are considered to be of lesser importance because the primary ion produced due to particle precipitation is $\mathrm{O}_{2}^{+}$.

In order to study the latitudinal extent of the SPE effects, SIC model runs were executed at six different magnetic latitudes between $60^{\circ} \mathrm{N}$ and $65^{\circ} \mathrm{N}$, with $1^{\circ}$ separation. Table 2 list both the magnetic and corresponding geographic locations of the model runs. An initialisation for January conditions and three model runs for the SPE period from 15 January 00:00 UT until 25 January 24:00 UT were executed for each of the locations. First run included no proton forcing, the second included time-varying proton forcing and magnetic cutoff, and the third included proton forcing but no magnetic cutoff. From here on we identify these as CTR, CUT, and SPE runs, respectively.

Left panels of Fig. 5 show the SIC-calculated CUT concentrations of $\mathrm{OH}$ during the SPE, at selected magnetic latitudes, and the right panels show the difference in $\mathrm{OH}$ concentration between the SPE and CUT runs. The increasing effect of magnetic cutoff with decreasing latitude is clearly visible. At $60^{\circ} \mathrm{N}$ and $65^{\circ} \mathrm{N}$ we see practically no effect and the full effect of the SPE, respectively. At the latitudes in between, the effects are seen especially on 18 January when the proton flux was high and cutoff energy was low. From the difference between the SPE and CUT runs, it is seen that the cutoff effect influences higher altitudes at higher latitudes, corresponding to the effect of rigidity cutoff removing the low-energy protons at high latitudes, which only impact at higher altitudes. In contrast, at lower latitudes the cutoff effect influences lower altitudes and increases in magnitude.

Figure 6 shows SIC-calculated $\mathrm{OH}$ concentrations at the cutoff transition latitudes at 63 and $74 \mathrm{~km}$ altitude on selected days of January, contrasting the difference between CTR, CUT, and SPE runs. On 15 January, the proton fluxes are at quiet-time levels. $\mathrm{OH}$ concentration is the same in all the three runs, i.e. the protons have a negligible effect at all latitudes. On the other days, the effects of proton forcing are clear and the cutoff transition region is easily defined. Largest difference between the SPE and CTR runs is seen on 18 January, together with high flux and low cutoff. On 19 January and 21 January lower proton fluxes result in clearly smaller changes in $\mathrm{OH}$ concentrations. Con- trasting the different altitudes on the same days and latitudes, the decrease due to cutoff sets in slightly stronger at higher altitudes. This is expected because higher energy protons, penetrating deeper into the atmosphere, experience relatively weaker cutoff than low-energy protons. The altitude differences are especially pronounced on 21 January when the cutoff energies were higher than on 19 January while the proton fluxes were about the same. On 19 January the cutoff transition region at $74 \mathrm{~km}$ is clearly wider in latitude than on 21 January when the transition between $64^{\circ} \mathrm{N}$ and $65^{\circ} \mathrm{N}$ is very sharp.

\section{Discussion}

Both the satellite data and model results show a clear latitudinal transition of the SPE effects, defining the region where the strength of forcing varies during the SPE, not only due to proton flux but also due to magnetic field changes. Comparing Fig. 4 and Fig. 6, the transition region is generally located at slightly lower latitudes in the data, at about $57-64^{\circ} \mathrm{N}$, than the $60-64^{\circ} \mathrm{N}$ predicted by the modelling, i.e. shifted equatowards by $2-3$ degrees. This "shift" of the transition region towards the lower latitudes is best seen under the high-flux low-cutoff conditions of 18 January. Therefore, the cutoff modelling seems to underpredict the extent of proton forcing by a few degrees, at least when the $K_{p}$ index is larger than 5 .

Rodger et al. (2006) concluded that the cutoff energies were underestimated by the model when $K_{p}>5$, resulting in a too much forcing by protons and too high ionospheric absorption when compared to the Halley riometer data. By saturating the $K_{p}$ at 6 , the agreement was found to improve. The data did not provide exact information on the extent of the proton forcing because all riometer beams were affected by cutoff effects. However, it was suggested that the need for $K_{p}$ restriction indicated that the stretching of the geomagnectic field was overestimated by the model, and that the latitudinal limit of the forcing was more poleward than predicted before.

Clilverd et al. (2007) tested the predictive accuracy of the Rodger model by comparing its results with Halley riometer observations during several SPE. They concluded that the $K_{p}$ saturation in the model leads to even better agreement with the data if enforced at 5.5 but only near the equatorial boundary of the proton forcing. For the poleward riometer beam, the adjustment of $K_{p}$ saturation limit did not improve comparison but a better agreement was obtained by moving the beam location 0.5 degrees equatowards. Again, the data did not exactly define the latitudinal extent of the forcing. The adjustments made suggest that the poleward boundary of the forcing is more equatoward than predicted by the model.

In the present study comparisons with hydroxyl data indicate that the poleward edge of the cutoff region is reasonable in the model to within $\approx 1^{\circ}$, but that the equatorward boundary is clearly shown to be more equatorward in the data. This 

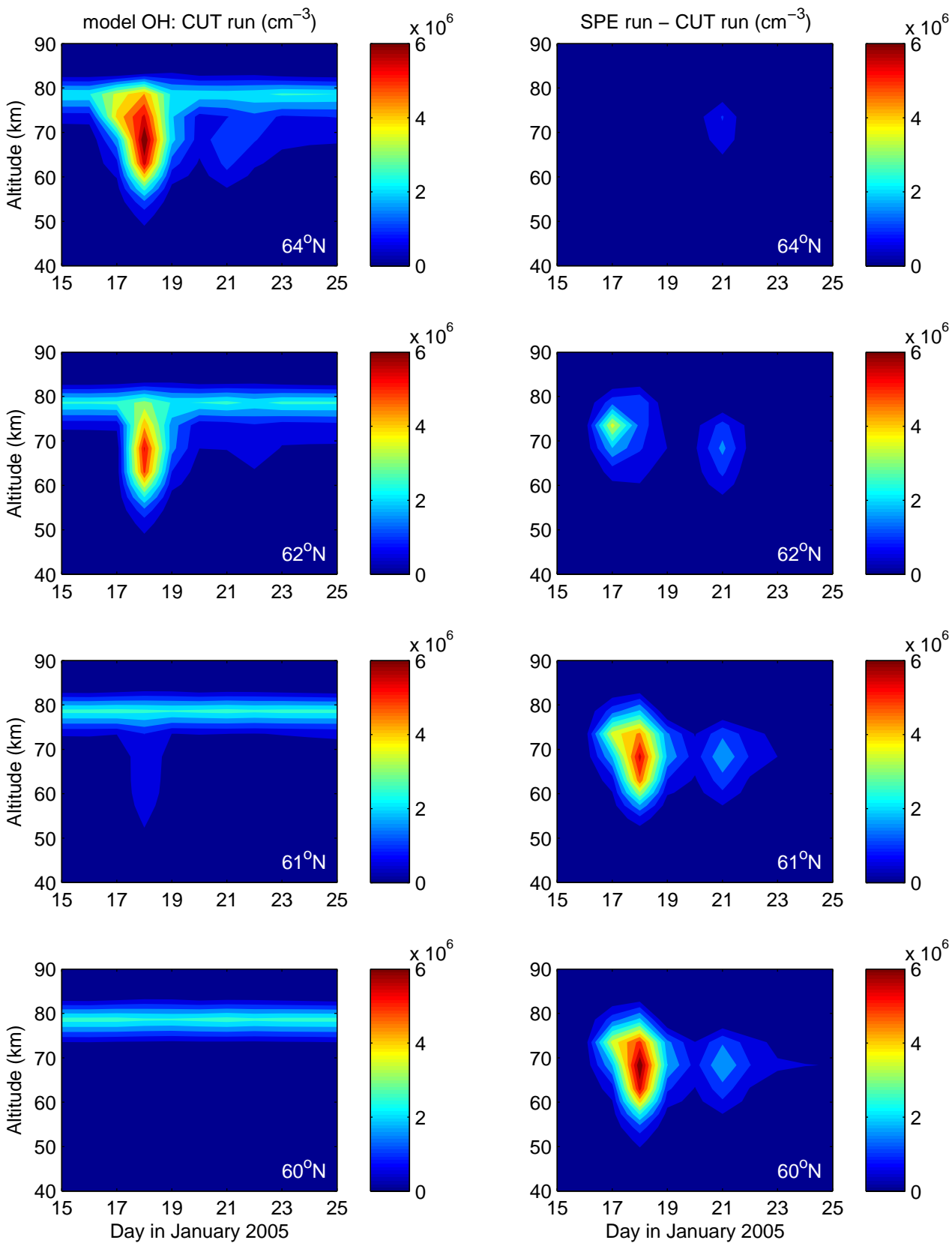

Fig. 5. Left panels: model $\mathrm{OH}$ at magnetic latitudes $60,61,62$, and $64^{\circ} \mathrm{N}$ (CUT run results). Concentrations are averages of 03:0006:00 UT, corresponding to 02:00-05:00 LT (geographic longitude is $15^{\circ} \mathrm{W}$ ). Right panels: The difference between the SPE (without cutoff) and CUT (with cutoff) runs.

is a useful addition to the knowledge about cutoff behaviour, because the Halley riometer is not adequately placed that a good idea of the equatorward boundary location could be obtained during big storms. Both Clilverd et al. (2007) and this study use the Rodger cutoff estimation method, with the $K_{p}$ saturated at 6 . So, the suggested over-stretching of the geomagnetic field is taken into account in these two studies. However, based on the hydroxyl data it seems that saturat- ing $K_{p}$ at 6 in the model, although leading to better contrast between riometer measurements and modelling in the cutoff transition region, also restricts the the latitudinal region of the forcing too much at the equatoward boundary. After repeating some of the model calculations with an extended latitude range, but without applying $K_{p}=6$ upper limit in the Rodger cutoff model, we found that the modelled cutoff transition region on 18 January is at $58^{\circ}-64^{\circ} \mathrm{N}$, as seen in Fig. 7, i.e. 

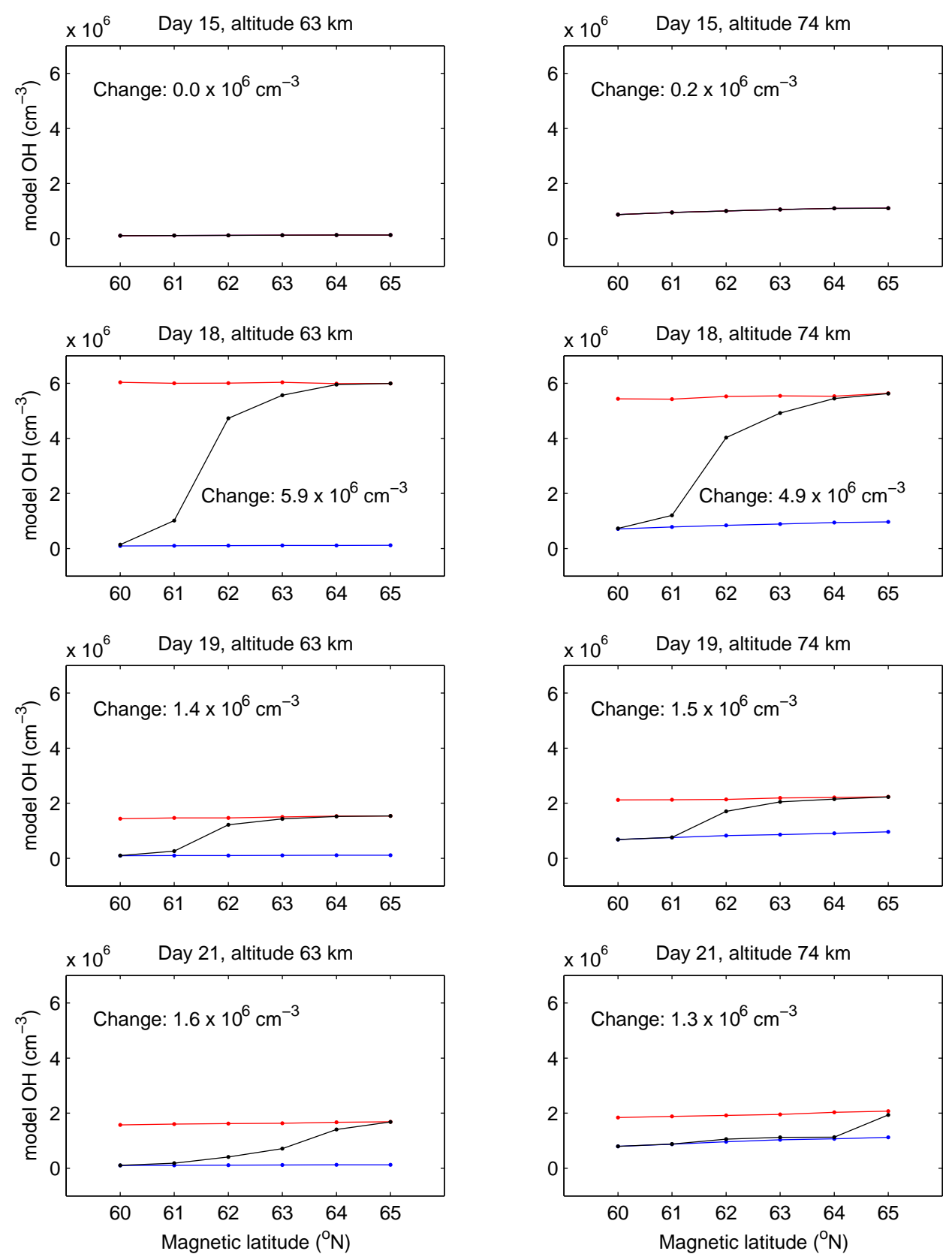

Fig. 6. Left panels: model OH at $63 \mathrm{~km}$ for selected days, the CTR (blue), CUT (black), and SPE (red) run results are shown at different magnetic latitudes. Change between the CTR and SPE concentrations are given for each of the panels. Right panels: Same as the left ones but at $74 \mathrm{~km}$ altitude.

more or less in agreement with the hydroxyl observations. It therefore seems the equatoward boundary is better represented by the cutoff model if the $K_{p}$ is not saturated.

These mixed results likely reflect the difficulty of predicting how geomagnetic field configures during significant magnetic storms when $K_{p}>6$. Rodger et al. (2006) demonstrated how geomagnetic field models struggle to reproduce the experimentally observed fields during highly disturbed geomagnetic conditions. Figure 9 of the Rodger paper contrasted L-values calculated using 5 different geomagnetic field models, all of which attempt to deal with geomagnetic storms. During highly disturbed conditions $\left(K_{p}>6\right)$, the Lvalues calculated varied from $\sim 5$ to $\sim 14.5$ depending on the model. There is no general agreement of which of these models is the "best" in representing the very disturbed magnetosphere. 
We have to note that comparison of $\mathrm{OH}$ data and model is not necessarily straight forward. This is mostly due to their different nature. The model provides results for a single location with varying local time, while the satellite measurements are sampled at approximately the same local time but on a different longitude with each orbit. On the other hand, $K_{p}$ is averaged over three hours in the modelling while the observation is a snapshot of the corresponding time. Averaging observations also averages $K_{p}$ conditions, and makes the signal-to-noise ratio better. Nevertheless, as seen in Fig. 4, the uncertainty in the data is generally larger than the observed increase in the transition region.

In addition to the latitude shift, there are other differences in the $\mathrm{OH}$ concentrations between the model and observations (see Figs. 3 and 5). The model underpredicts the $\mathrm{OH}$ concentration around $80 \mathrm{~km}$ altitude, and overpredicts it around $65 \mathrm{~km}$. A possible factor contributing to these differences are the uncertainties of the water vapour amount in the model. Although we use MLS observations of $\mathrm{H}_{2} \mathrm{O}$ in SIC, this data might be too strongly influenced by the a priori at mesospheric altitudes (Livesey et al., 2005). On the other hand, sensitivity of the model $\mathrm{OH}$ results to the amount of $\mathrm{H}_{2} \mathrm{O}$ has previously been found to be relatively strong (Verronen et al., 2006). Another possible reason for the differences could be the assumptions made concerning proton spectra, especially on 20 January when the spectrum was unusually hard. Our approach is to use measurements of the GOES-11 satellite as a starting point and convert its energy channels into a continuous proton flux spectrum. This method, originally presented by Reid (1961) and described more recently by Verronen et al. (2005), has in the past been succesfull in describing the proton fluxes affecting the middle atmospheric altitudes, also during the January 2005 SPE (Clilverd et al., 2006b; Seppälä et al., 2006). Nevertheless, we checked the hard-spectra period during 20 January 06:00 UT-20 January 12:00 UT and, although the spectra show an unusual second peak at energies greater than $30 \mathrm{MeV}$, we found the spectrum construction method itself clearly works (not shown). In addition, none of data or model results we show in this paper are taken from the hard-spectrum period, and are likely not significantly affected by it because of the relatively short photochemical lifetime of hydroxyl. We are therefore rather confident that no significant reason for the discrepancies arises due to the description of the proton spectra.

A factor possibly affecting our results is energetic electron precipitation (EEP), which could be occurring simultaneously with the SPE. In theory, the EEP can be included in the SIC model if the electron fluxes are known. The flux determination is not straight forward though, because the satellite observations are particularly hard to make successfully due to the very narrow size of the electron bounce loss cone. For most of the outer radiation belts, the loss cone is too narrow to be clearly resolved by existing satellite-borne particle detectors. In the present case, we have no data available to us which could be used to check if electron precipitation oc-

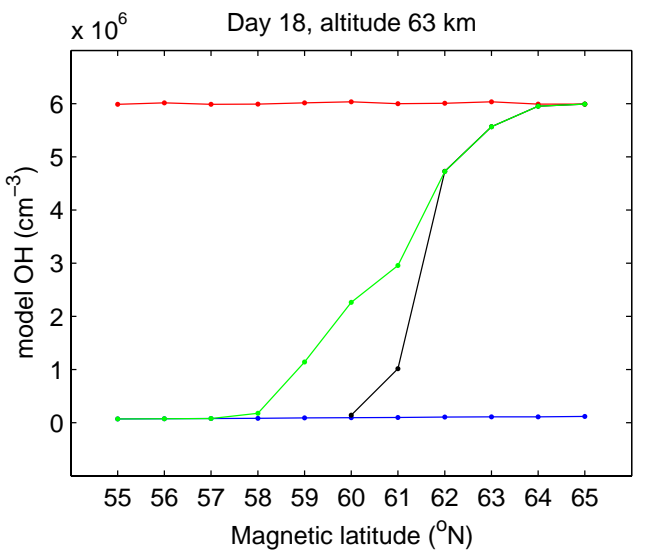

Fig. 7. Model $\mathrm{OH}$ at $63 \mathrm{~km}$ on 18 January, the CTR (blue), CUT (black, $K_{p}$ saturated at 6), and SPE (red) run results are shown at different magnetic latitudes. The green line shows the CUT run results when $K_{p}$ is not forced to values $\leq 6$.

curred or not during January 2005. Based on the study by Clilverd et al. (2006a), there was significant electron precipitation late on 21 January, with some indication that the invariant magnetic latitude range affected was $60-66^{\circ} \mathrm{N}$ in the pre-midnight sector. In the bottom panels of Fig. 4, showing the data for early 21 January, increases are seen at latitudes larger than $59^{\circ} \mathrm{N}$, which is consistent with the observed EEP latitudes. Throughout the storm period (15-25 January) some EEP would be expected as injected/accelerated electrons are gradually lost to the atmosphere from the radiation belts (Abel and Thorne, 1998; Horne, 2002). These typically cover the range $54-69^{\circ} \mathrm{N}$, and might be expected to contribute to some of the $\mathrm{OH}$ production at some of these latitudes depending on the loss mechanism involved. Thus it is possible that EEP is generating some of the increase of $\mathrm{OH}$ between $57-60^{\circ} \mathrm{N}$, and that this could explain the difference between the satellite observations and the model results. Conversely we would also expect to see some effects as far equatorwards as $\sim 54^{\circ} \mathrm{N}$ if this were the case. Further modelling of EEP in this context is required.

\section{Summary}

We have studied the latitudinal extent of the solar proton event which occurred in January 2005. Hydroxyl measurements from MLS/Aura instrument were used to define the transition region where the SPE forcing depends upon the time-varying magnetic rigidity cutoff imposed by the Earth's magnetic field. The observations were compared to the hydroxyl results from the Sodankylä Ion and Neutral Chemistry model, which takes into account the time-varying, latitudedependent proton cutoff energies by a method based on magnetospheric modelling and particle-tracing studies. 
The observations show the cutoff transition region generally from 57 to 64 degrees of magnetic latitude, varying with proton flux and the $K_{p}$ magnetic index. The model results are in reasonable agreement with the observations. However, when using the $K_{p}$ upper limit 6 in the cutoff modelling, as suggested by Rodger et al. (2006), the location of the equatoward boundary of the transition region is more polewards than seen in the data, by 2-3 degrees in latitude, leading to an underestimation of the extent of the proton forcing. If the $K_{p}$ index is allowed to vary within its nominal range between $1-9$, the equatoward boundary predicted by the modelling agrees with the observations within $1^{\circ}$ of latitude.

Acknowledgements. Research at the Jet Propulsion Laboratory, California Institute of Technology, is performed under contract with the National Aeronautics and Space Administration. GOES proton flux data were provided by the SPIDR online data repository. MLS hydroxyl and water vapour data were provided by the NASA EOS Data Gateway. The two anonymous referees helped to improve the paper significantly.

Topical Editor I. A. Daglis thanks D. Smart and another anonymous referee for their help in evaluating this paper.

\section{References}

Abel, B. and Thorne, R. M.: Electron scattering loss in Earth's inner magnetosphere 2. Sensitivity to model parameters, J. Geophys. Res., 103, 2397-2408, 1998.

Banks, P. M. and Kockarts, G.: Aeronomy, Academic Press, Part B, chapter 15, 1973.

Birch, M. J., Hargreaves, J. K., Senior, A., and Bromage, B. J. I.: Variations in cutoff latitude during selected solar energetic proton events, J. Geophys. Res., 110, A07 221, doi:10.1029/ 2004JA010833, 2005.

Brasseur, G. P. and Solomon, S.: Aeronomy of the Middle Atmosphere, Springer, Dordrecht, 3rd revised and enlarged edn., 2005.

Chabrillat, S., Kockarts, G., Fonteyn, D., and Brasseur, G.: Impact of molecular diffusion on the $\mathrm{CO}_{2}$ distribution and the temperature in the mesosphere, Geophys. Res. Lett., 29, 1-4, 2002.

Clilverd, M. A., Rodger, C. J., and Ulich, T.: The importance of atmospheric precipitation in storm-time relativistic electron flux drop outs, Geophys. Res. Lett., 33, L01 102, doi:10.1029/ 2005GL024661, 2006a.

Clilverd, M. A., Seppälä, A., Rodger, C. J., Thomson, N. R., Verronen, P. T., Turunen, E., Ulich, T., Lichtenberger, J., and Steinbach, P.: Modelling polar ionospheric effects during the OctoberNovember 2003 solar proton events, Radio Sci., 41, RS2001, doi: 10.1029/2005RS003290, 2006b.

Clilverd, M. A., Rodger, C. J., Moffat-Griffin, T., and Verronen, P. T.: Improved dynamic geomagnetic rigidity cutoff modelling: Testing predictive accuracy, J. Geophys. Res., 112, A08 302, doi: 10.1029/2006JA012410, 2007.

Dobbin, A. L., Aylward, A. D., and Harris, M. J.: Threedimensional GCM modeling of nitric oxide in the lower thermosphere, J. Geophys. Res., 111, A07 314, doi:10.1029/ 2005JA011543, 2006.

Dyer, C. S., Lei, F., Clucas, S. N., Smart, D. F., and Shea, M. A.: Calculations and observations of solar particle enhancements to the radiation environment at aircraft altitudes, Adv. Space Res., 32, 81-93, 2003.

Grenfell, J. L., Lehmann, R., Mieth, P., Langematz, U., and Steil, B.: Chemical reaction pathways affecting stratospheric and mesospheric ozone, J. Geophys. Res., 111, D17311, doi: 10.1029/2004JD005713, 2006.

Hargreaves, J. K.: The solar-terrestrial environment, Cambridge Atmospheric and Space Science Series, Cambridge University Press, Cambridge, UK, 1992.

Heaps, M. G.: The effect of a solar proton event on the minor neutral constituents of the summer polar mesosphere, Rep. ASLTR0012, U.S. Army Atmos. Sci. Lab., White Sands Missile Range, N. M., 1978.

Hedin, A. E.: Extension of the MSIS Thermospheric Model into the Middle and Lower Atmosphere, J. Geophys. Res., 96, 1159$1172,1991$.

Horne, R. B.: The contribution of wave-particle interactions to electron loss and acceleration in the Earth's radiation belts during geomagnetic storms, pp. 801-828, URSI Review of Radio Science 1999-2002, edited by: Stone, W. R., Wiley, 2002.

Jackman, C. H., Cerniglia, M. C., Nielsen, J. E., Allen, D. J., Zawodny, J. M., McPeters, R. D., Douglass, A. R., Rosenfield, J. E., and Hood, R. B.: Two-dimensional and three-dimensional model simulations, measurements, and interpretation of the October 1989 solar proton events on the middle atmosphere, J. Geophys. Res., 100, 11641-11660, 1995.

Jackman, C. H., McPeters, R. D., Labow, G. J., Fleming, E. L., Praderas, C. J., and Russel, J. M.: Northern hemisphere atmospheric effects due to the July 2000 solar proton events, Geophys. Res. Lett., 28, 2883-2886, 2001.

Kress, B. T., Hudson, M. K., Perry, K. L., and Slocum, P. L.: Dynamic modeling of geomagnetic cutoff for the 23-24 November 2001 solar energetic particle event, Geophys. Res. Lett., 31, L04 804, doi:10.1029/2003GL018599, 2004.

Livesey, N. J., Read, W. G., Filipiak, M. J., Froidevaux, L., Harwood, R. S., Jiang, J. H., Jimenez, C., Pickett, H. M., Pumphrey, H. C., Santee, M. L., Schwartz, M. J., Waters, J. W., and Wu, D. L.: EOS MLS Version 1.5 Level 2 data quality and description document, JPL D-32381, Jet Propulsion Laboratory, Version 1.51, 29 July 2005.

Ogliore, R. C., Mewald, R. A., Leske, R. A., Stone, E. C., and von Rosenvinge, T. T.: A direct measurement of the geomagnetic cutoff for cosmic rays at Space Station latitudes, Proc. Int. Conf. Cosmic Rays, 27th, 4112-4115, 2001.

Patterson, J. D., Armstrong, T. P., Laird, C. M., Detrick, D. L., and Weatherwax, A. T.: Correlation of solar energetic protons and polar cap absorption, J. Geophys. Res., 101, 149-163, 2001.

Pickett, H. M., Drouin, B. J., Canty, T., Kovalenko, L. J., Salawitch, R. J., Livesey, N. J., Read, W. G., Waters, J. W., Jucks, K. W., and Traub, W. A.: Validation of Aura MLS $\mathrm{HO}_{\mathrm{x}}$ measurements with remote-sensing balloon instruments, Geophys. Res. Lett., 33, L01 808, doi:10.1029/2005GL024048, 2006.

Pickett, H. M., Read, W. G., Lee, K. K., and Yung, Y. L.: Observation of night $\mathrm{OH}$ in the mesosphere, Geophys. Res. Lett., 33, L19 808, doi:10.1029/2006GL026910, 2006.

Reames, D. V.: Particle acceleration at the Sun and in the heliosphere, Space Sci. Rev., 90, 413-491, 1999.

Reid, G. C.: A study of the enhanced ionization produced by solar protons during a polar cap absorbtion event, J. Geophys. Res., 
66, 4071-4085, 1961.

Reid, G. C., Solomon, S., and Garcia, R. R.: Response of the middle atmosphere to the solar proton events of August-December, 1989, Geophys. Res. Lett., 18, 1019-1022, 1991.

Rodger, C. J., Clilverd, M. A., Verronen, P. T., Ulich, T., Jarvis, M. J., and Turunen, E.: Dynamic geomagnetic rigidity cutoff variations during a solar proton event, J. Geophys. Res., 111, A04 222, doi:10.1029/2005JA011395, 2006.

Rusch, D. W., Gérard, J.-C., Solomon, S., Crutzen, P. J., and Reid, G. C.: The effect of particle precipitation events on the neutral and ion chemistry of the middle atmosphere - I. Odd nitrogen, Planet. Space Sci., 29, 767-774, 1981.

Seppälä, A., Verronen, P. T., Kyrölä, E., Hassinen, S., Backman, L., Hauchecorne, A., Bertaux, J. L., and Fussen, D.: Solar Proton Events of October-November 2003: Ozone depletion in the Northern hemisphere polar winter as seen by GOMOS/Envisat, Geophys. Res. Lett., 31, L19 107, doi:10.1029/2004GL021042, 2004.

Seppälä, A., Verronen, P. T., Sofieva, V. F., Tamminen, J., Kyrölä, E., Rodger, C. J., and Clilverd, M. A.: Destruction of the Tertiary Ozone Maximum During a Solar Proton Event, Geophys. Res. Lett., 33, L07 804, doi:10.1029/2005GL025571, 2006.

Shimazaki, T.: Effective eddy diffusion coefficient and atmospheric composition in the lower thermosphere, J. Atmos. Terr. Phys., 33, 1383, 1971.

Shimazaki, T.: Minor Constituents in the Middle Atmosphere (Developments in Earth and Planetary Physics, No 6), D. Reidel Publishing Co., Dordrecht, Holland, 1984.

Smart, D. F. and Shea, M. A.: Comparison of the Tsyganenko model predicted and measured geomagnetic cutoff latitudes, Adv. Space Res., 28, 1733-1738, 2001.

Smart, D. F. and Shea, M. A.: Geomagnetic cutoff rigidity calculations at 50-year intervals between 1600 and 2000, Proc. Int. Conf. Cosmic Rays, 29th, 4201-4204, 2003.
Solomon, S., Rusch, D. W., Gérard, J.-C., Reid, G. C., and Crutzen, P. J.: The effect of particle precipitation events on the neutral and ion chemistry of the middle atmosphere: II. Odd hydrogen, Planet. Space Sci., 8, 885-893, 1981.

Størmer, C.: Periodische Elektronenbahnen im Feld eines Elementramagnetron und ihre Anwendung auf Bruches Modellversuche und auf Eschenhagens Elementarwellen des Erdmagnetismus, Zeitschr. f. Astrophys., 1, 237-274, 1930.

Thomas, L. and Bowman, M. R.: A study of pre-sunrise changes in negative ions and electrons in the D-region, J. Atmos. Terr. Phys., 4, 219, 1986.

Tobiska, W. K., Woods, T., Eparvier, F., Viereck, R., Floyd, L. D. B., Rottman, G., and White, O. R.: The SOLAR2000 empirical solar irradiance model and forecast tool, J. Atmos. Terr. Phys., 62, 1233-1250, 2000.

Tsyganenko, N. A.: Determination of magnetospheric current system parameters and development of experimental geomagnetic models based on data from IMP and HEOS satellites, Planet. Space Sci., 37, 5-20, 1989.

Turunen, E., Matveinen, H., Tolvanen, J., and Ranta, H.: D-region ion chemistry model, in: STEP Handbook of Ionospheric Models, edited by: Schunk, R. W., pp. 1-25, SCOSTEP Secretariat, Boulder, Colorado, USA, 1996.

Verronen, P. T.: Ionosphere-Atmosphere Interaction During Solar Proton Events, Ph.D. thesis, University of Helsinki (available at http://ethesis.helsinki.fi), 2006.

Verronen, P. T., Seppälä, A., Clilverd, M. A., Rodger, C. J., Kyrölä, E., Enell, C.-F., Ulich, T., and Turunen, E.: Diurnal variation of ozone depletion during the October-November 2003 solar proton events, J. Geophys. Res., 110, A09S32, doi: 10.1029/2004JA010932, 2005.

Verronen, P. T., Seppälä, A., Kyrölä, E., Tamminen, J., Pickett, H. M., and Turunen, E.: Production of odd hydrogen in the mesosphere during the January 2005 solar proton event, Geophys. Res. Lett., 33, L24 811, doi:10.1029/2006GL028115, 2006. 